\title{
A new 3-D modelling method to extract subtransect dimensions from underwater videos
}

\author{
L. Fillinger and T. Funke \\ Alfred-Wegener-Institut Helmholtz-Zentrum für Polar- und Meeresforschung, Am Alten Hafen 26, \\ 27568 Bremerhaven, Germany \\ Correspondence to: L. Fillinger (laura.fillinger@awi.de) \\ Received: 13 November 2012 - Published in Ocean Sci. Discuss.: 20 December 2012 \\ Revised: 13 March 2013 - Accepted: 20 March 2013 - Published: 16 April 2013
}

\begin{abstract}
Underwater video transects have become a common tool for quantitative analysis of the seafloor. However a major difficulty remains in the accurate determination of the area surveyed as underwater navigation can be unreliable and image scaling does not always compensate for distortions due to perspective and topography. Depending on the camera set-up and available instruments, different methods of surface measurement are applied, which make it difficult to compare data obtained by different vehicles. 3-D modelling of the seafloor based on 2-D video data and a reference scale can be used to compute subtransect dimensions. Focussing on the length of the subtransect, the data obtained from 3-D models created with the software PhotoModeler Scanner are compared with those determined from underwater acoustic positioning (ultra short baseline, USBL) and bottom tracking (Doppler velocity log, DVL). 3-D model building and scaling was successfully conducted on all three tested set-ups and the distortion of the reference scales due to substrate roughness was identified as the main source of imprecision. Acoustic positioning was generally inaccurate and bottom tracking unreliable on rough terrain. Subtransect lengths assessed with PhotoModeler were on average $20 \%$ longer than those derived from acoustic positioning due to the higher spatial resolution and the inclusion of slope. On a high relief wall bottom tracking and 3-D modelling yielded similar results. At present, 3-D modelling is the most powerful, albeit the most time-consuming, method for accurate determination of video subtransect dimensions.
\end{abstract}

\section{Introduction}

With the advantage of being non-destructive, underwater imagery has become a common scientific tool for quantitative studies of the seafloor (Solan et al., 2003). This is due to an improvement of imaging technology (Kocak et al., 2008; Schettini and Corchs, 2010; Bonin et al., 2011) and the development of platforms such as sledges (Shortis et al., 2008; Jones et al., 2009), remotely operated vehicles (ROV) (Sedlazeck et al., 2009; Karpov et al., 2012; Lindsay et al., 2012; Stierhoff et al., 2012), autonomous underwater vehicles (AUV) (Dowdeswell et al., 2008) and manned submersibles (Chevaldonné and Jollivet, 1993; Tissot et al., 2007). Although different methods are available for underwater positioning and image scaling, practical considerations complicate the processing of the data in a quantitative way.

The main instruments on these vehicles are video and still cameras employed for both piloting and analysis. Their orientation plays a major role in data processing. In the past, the camera axis was set perpendicular to the substrate in order to reduce distortions in the images and ease scaling (Pilgrim et al., 2000). This strategy is still applied for estimation of sponge densities (Chu and Leys, 2010), determination of algal cover below ice (Ambrose et al., 2005), mapping of hydrothermal vents (Cuvelier et al., 2009) and mosaicking (Garcia et al., 2001; Jerosch et al., 2007). Vertical set-ups facilitate the calculation of area for quantitative outputs. Oblique cameras offer a more natural view making identification and piloting easier (Jones et al., 2009) but scaling more challenging due to distortions resulting from perspective (Wakefield and Genin, 1987). The deployment of two cameras, one forward-looking and the other tilted 
toward the substrate provides an ideal configuration (Karpov et al., 2006; Dolan et al., 2008; Guinan et al., 2009). However small ROVs often have only a single camera with reduced tilting capacity (Auster et al., 1989). Nevertheless, several studies have successfully exploited videos from cameras oriented 0 to 50 degrees below the horizontal for the evaluation of fish densities (Pinkard et al., 2005; Söffker et al., 2011), megabenthos abundance (Smith and Hamilton, 1983; Cranmer et al., 2003; Ruhl, 2007; Post et al., 2011), deep water coral communities (Post et al., 2010), king crab population size (Smith et al., 2012) and polychaete biomass (Chevaldonné and Jollivet, 1993).

The most widespread sampling strategy in the deployment of underwater cameras is the execution of line transects (e.g. Post et al., 2010; Karpov et al., 2012; Smith et al., 2012); however, surveying points regularly distributed on a grid may provide an alternative (Chu and Leys, 2010). The general attitude of the vehicle carrying the camera during a transect is a delicate issue as it can greatly complicate the postprocessing and hence increase the time invested in analysis (Jones et al., 2009). Usually the pilot tries to keep the distance to the substrate (Anderson and Yoklavich, 2007), the heading (Ambrose et al., 2005; Cuvelier et al., 2009) and the speed constant (Jones et al., 2006; Karpov et al., 2012).

Once images have been acquired, the area covered by the complete video transect, by subtransects or by single pictures (stills or extracted video frames) has to be determined in order to be able to assess quantitative data such as abundances and densities of organisms (Auster et al., 1989).

Usual methods for the scaling of single frames, appropriate for relatively flat habitats, rely on algorithms based on knowledge of the distance to the substrate and on the camera properties to estimate the size of the field of view (e.g. Jerosch et al., 2007; Guinan et al., 2009; Stierhoff et al., 2012), the use of parallel lasers as references (e.g. Pinkard et al., 2005; Baker et al., 2012b) or the overlay on the pictures of a perspective grid as described in Wakefield and Genin (1987) (e.g. Pilgrim et al., 2000; Pinkard et al., 2005; Smith et al., 2012).

While working on videos, especially with oblique cameras, the area surveyed can be calculated by multiplying the centre width of the frames, obtained by one of the scaling methods previously cited, by the length of the transect or the subtransect (Auster et al., 1989; Pinkard et al., 2005). This length might be derived from underwater navigation data (Auster et al., 1989) using an equal area projection in a geographic information system software to cipher the distance travelled by the vehicle (Tissot et al., 2007; Karpov et al., 2006, 2012). The choice of the geographic coordinate system can greatly impact the results as an inadequate projection would lead to high distortions, especially in polar regions (Sievers and Bennat, 1989). Transect length might also be evaluated from the speed recorded by a Doppler velocity $\log$ (DVL) (Pinkard et al., 2005; Snyder, 2010; Stierhoff et al., 2012) or read directly from the DVL bottom track data (Kocak et al., 2004).

Other means have been suggested for area determination, e.g. measuring distances between features on bathymetric charts (Karpov et al., 2006), flying over a known length of tether from a weight (Auster et al., 1989), using a weighted wheel bound to an odometer (Pollio, 1969), deploying a scale (Patterson et al., 2009), frames (Kocak et al., 2004; AmadoFilho et al., 2012) or using objects of known size as scaling references (Jones et al., 2006, 2009).

To sum up, the complexity of the scaling process depends on the camera system employed and the attitude sensors available on the vehicle: it is easier to scale vertical images with a constant field of view than to calculate the area surveyed by an oblique camera with variable tilt, altitude and speed (Pinkard et al., 2005).

Relief and substrate roughness can also be an issue as they may affect some instruments such as lasers (Karpov et al., 2006) and DVLs (Pinkard et al., 2005) and result in significant differences between the actual distance travelled and the track length computed from the navigation system (Barry and Baxter, 1993). In habitats with a rough small-scale topography, difficulties arise as complex 3-D structures are represented on 2-D images: all visible surfaces are not located at the same distance to the camera nor viewed from the same angle and hence appear at different scales on the images. None of the previously cited scaling methods is able to account for this.

Nowadays, a plethora of underwater videos and pictures are available, from regions all around the globe (e.g. Arctic: Laudien and Orchard, 2012, Antarctic: Gutt and Starmans, 2001, tropics: Carleton and Done, 1995). They cover all depth ranges (e.g. photic zone: Parry et al., 2002, continental slope: Baker et al., 2012a, deep sea: Chevaldonné and Jollivet, 1993) but represent a very heterogeneous assemblage of video quality, camera orientation and methods used to calculate the area covered by the survey. This becomes problematic when spatial or temporal comparisons have to be realized.

The solution imagined was to create scaled 3-D models of the portion of substrate visible in underwater videos from which the dimensions of several subtransects could be derived. For this purpose PhotoModeler Scanner (EOS Systems) was used: a commercially available 3-D modelling software which triangulates the position of various points on an object or a surface from pictures representing different views of this object. The point cloud obtained can then be scaled by entering one or several known distances, named here scaling references, to allow measurements between any two points within the model (Ewins and Pilgrim, 1997). PhotoModeler was initially developed for land-based work. In an aquatic environment, turbidity and image distortions might impact the accuracy of the 3-D model (Ewins and Pilgrim, 1997). In addition, artificial lighting results in the centre of underwater images being brighter than the edges (Schettini 
and Corchs, 2010) so that differences in brightness could also disturb the process of 3-D reconstruction as the colours are distorted while the camera moves (Sedlazeck et al., 2009). Ewins and Pilgrim (1997) found the software suitable for underwater work. It has been successfully employed for morphometric analysis on corals (Bythell et al., 2001) and mapping of submarine archaeological sites (Green et al., 2002; Green and Gainsford, 2003). The advantage of this method is that it only bases on overlapping images and a scale and should thus be applicable to the majority of the underwater videos readily available. Furthermore, as 3-D information can be regained from 2-D images, this could be especially useful in habitats with a rough small-scale topography.

Here, we describe a method of subtransect length computation from 3-D models of the seafloor created with PhotoModeler from ROV videos. We also evaluate this technique on videos showing different qualities and orientation, using two scaling references on two types of substrate. Finally, we compare the subtransect lengths obtained via 3-D modelling with distances estimated from underwater navigation data and DVL bottom tracking.

\section{Methods}

\subsection{Video material: sites and set-ups}

Video material from three dives with different ROVs was used to evaluate the feasibility of 3-D modelling with PhotoModeler aiming at subtransect length measurements. The key parameters of the sites and set-ups are summarized in Table 1.

\subsubsection{Dive A}

The video data for the first 3-D reconstruction originated from a dive at station PS69/724-1 (64 54.9' $\left.\mathrm{S}, 60^{\circ} 39.15^{\prime} \mathrm{W}\right)$ during the expedition ANT-XXIII/8 of R/V Polarstern in January 2007 in the Larsen Ice Shelf area (Antarctic Peninsula). The substrate was relatively flat and composed of mud, sand and pebbles with depths varying from 146 to $190 \mathrm{~m}$. The ROV "Cherokee" (sub-Atlantic) owned by Marum, University of Bremen, Germany was deployed. It was equipped with a forward looking standard definition (SD: $720 \times 576 \mathrm{px}$, progressive, $25 \mathrm{fps}, 25 \mathrm{Mbps}$ ) video camera (Tritech Typhoon PAL, lens: $3.6-82.8 \mathrm{~mm}$, F1.6-F3.6), a still camera (Nikon Coolpix 995) and an additional overview camera (DSPL MultiSeacam color PAL), illuminated by three 500 W LEDs (ROS QLED III). Two parallel red lasers (ILEE LDA1000) pointing into the centre of the SD video provided a reference scale of $20 \mathrm{~cm}$. Additional navigation sensors were available: a mechanical scanning sonar (Tritech super SeaKing), a pan and tilt unit, an altimeter (Tritech PA500) and a manipulator (Hydrolek, EH5) for sampling. The underwater position of the vehicle was not available. The video signal from the SD camera was recorded on mini-DV (.avi,
DV (digital video)). During the entire dive, the pilot tried to keep the heading and distance to the seabed constant, following the ship's track.

\subsubsection{Dive B}

A second dive was realized at approximately the same site as dive A in March 2011, at station PS77/253-1 (64 54.82' S, $60^{\circ} 39.06^{\prime} \mathrm{W}$ ) during the R/V Polarstern ANT-XXVII/3 expedition. Depth varied from 143 to $167 \mathrm{~m}$. A ROV (Sperre SubFighter 7500 DC) belonging to the Sven Lovén Centre for Marine Sciences, University of Gothenburg, Sweden was deployed with one forward looking high definition (HD: $1920 \times 1080 \mathrm{px}$, interlaced, $50 \mathrm{fps}, 50 \mathrm{Mbps}$ ) video camera (Sony FCBH11, lens: 5.1-51 mm, F1.8-F2.1), two standard video cameras for navigation and umbilical surveillance and one still camera (Canon Powershot G9). Two parallel red lasers (Deep Sea Systems) placed $5 \mathrm{~cm}$ apart were projected in the centre of the HD video for scaling. Lighting was ensured by two $200 \mathrm{~W}$ HMI (hydrargyrum medium arc-length iodide) lights (Sperre) and two $250 \mathrm{~W}$ halogen lights. The vehicle also carried a scanning sonar (Kongsberg Mesotech), a CTD (Conductivity-Temperature-Depth recorder; Saiv SD204) and a manipulator (Hydrolek EH5). Underwater position was determined via the ultra short baseline (USBL) system Posidonia (Ixsea) linked to the GPS system on-board R/V Polarstern. The USBL data (latitude, longitude and depth) was imported into the ROV data processing software OFOP (Ocean Floor Observation Protocol) (Huetten and Greinert, 2008) for real time display and recording of the vehicle position. All videos were relayed to the surface control room and the HD stream was saved to compact flash cards (.mov, .mpeg2) with a nanoFlash recorder (Convergent Design). The dive alternated between short (10 min) line transects where the pilot kept the heading, speed and altitude constant and periods where the vehicle remained immobile for sampling and small-scale observations.

\subsubsection{Dive C}

The third data set was recorded in February 2012 during the expedition Errina_2012 on M/V Explorador. The station Errina2012_GD $\left(51^{\circ} 10.14^{\prime} \mathrm{S}, 74^{\circ} 56.171^{\prime} \mathrm{W}\right)$ was located in the steep-sloped Guadalupe Channel in Chilean Patagonia. The substrate was composed of stony walls alternating with slides of finer sediment resulting in a rough habitat topography marked by small-scale variations in slope angle and orientation down to $150 \mathrm{~m}$. The ROV, a V8 Sii (Ocean Modules) customized for the Alfred Wegener Institute, Germany, carried two HD $(1920 \times 1080 \mathrm{px}$, interlaced $60 \mathrm{fps}$, $50 \mathrm{Mbps})$ video cameras (Kongsberg oe14-502, lens: 5.1-51 mm, F1.8F2.1): one oriented horizontally and the other tilted $30^{\circ}$ downward for navigation and data analysis. A wide angle camera (Bowtech L3C-550) observed the rear to control the manipulator (Sub-Atlantic MK 1) and the tether. An echo 
Table 1. Main parameters of the sites and set-ups for the three ROV dives.

\begin{tabular}{lllllll}
\hline Dive & Site & $\begin{array}{l}\text { Substrate } \\
\text { topography }\end{array}$ & $\begin{array}{l}\text { Camera } \\
\text { definition }\end{array}$ & $\begin{array}{l}\text { Camera } \\
\text { orientation }\end{array}$ & $\begin{array}{l}\text { Scaling } \\
\text { reference }\end{array}$ & $\begin{array}{l}\text { Other length } \\
\text { measurements }\end{array}$ \\
\hline A & Antarctic & Smooth & Standard & Oblique & Lasers $20 \mathrm{~cm}$ & None \\
B & Antarctic & Smooth & High & $\begin{array}{l}\text { Oblique } \\
\text { Perpendicular } \\
\text { to substrate }\end{array}$ & $\begin{array}{l}\text { Lasers } 5 \mathrm{~cm} \\
\text { Altimeter }\end{array}$ & USBL \\
Chile & Rough & High & & & \\
\hline
\end{tabular}

sounder (Tritech Micron) was mounted onto the tilted camera to measure its distance to the substrate (Karpov et al., 2006). Light was provided by five LEDs (Bowtech LED2400 aluminium): four in the front and one at the rear. An obstacle avoidance sonar (Tritech Micron) facilitated the navigation and a Doppler velocity log (RDI Explorer PA) orientated in the same direction as the tilted camera was used for bottom tracking and current measurements. Depth was obtained from the inertial measurement unit (IMU) and the CTD (SeaBird SBE19 plus). The USBL positioning system (Tritech MicroNav) was linked to a differential GPS (Geneq SX Blue II) and the position of the vehicle was plotted and recorded in the Seanet software (Tritech). Data from the DVL were displayed and registered in WinRiver II (RDI). The HD video streams were captured to compact flash cards (.mxf, .mpeg2) by a nanoFlash recorder (Convergent Design). The strategy adopted on this site was to exploit the ROV's 360 degrees manoeuvrability and fly several short (estimated $15 \mathrm{~m}$ from the DVL bottom track) horizontal transects at given depths by moving sideways, thus keeping the tilted camera axis perpendicular to the channel's wall. The pitch was adapted to the slope and the speed, heading and distance to the substrate were kept as constant as possible. Nevertheless, navigation was difficult due to the rough habitat topography and the presence of obstacles (stones, overhangs) on the trajectory requiring careful adjustment of the vehicle.

\subsection{Determination of subtransect length}

Figure 1 gives an overview of the different steps necessary to obtain subtransect measurements from 3-D models, USBL underwater acoustic navigation and from DVL bottom tracking.

\subsubsection{PhotoModeler}

To create 3-D models with PhotoModeler Scanner overlapping pictures along the transects and a scale are needed. Videos were trimmed to consistent sequences (.mpg, .mpeg2) of stable vehicle speed, heading, tilt and distance to the substrate with Freemake video converter. Free studio (DVDVideoSoft) was then used to extract as .jpeg every tenth frame for dive A and B (Antarctic) and every twentieth frame for dive $C$ (Chile, tilted camera). In order to minimize the dis- turbances due to artificial lightning, the edges of the pictures were cropped in XnView by up to $10 \%$ vertically and horizontally. With these settings, any feature was seen from at least 8 angles as recommended in previous studies using PhotoModeler or similar software (Bythell et al., 2001; Cocito et al., 2003; Green and Gainsford, 2003; de Bruyn et al., 2009).

The frames obtained were imported into PhotoModeler Scanner and an automated "SmartPoints project" was run. During this processing, the software first automatically detects natural features in each picture and marks them as "SmartPoints" (Fig. 2). Based on its characteristics (position, shape, scale) each feature is then identified on consecutive pictures and its displacements followed up. From these movements, a programme routine reconstructs the relative position of the camera from which each picture was taken (Fig. 3). Finally, the relative 3-D position of each SmartPoint is solved, resulting in a 3-D points cloud (Fig. 4). While several of the 3-D reconstruction algorithms developed in the last decade have been published (Pizarro et al., 2004; Brandou et al., 2007; Sedlazeck et al., 2009; Beall et al., 2010), the algorithm running in PhotoModeler, a commercial software, is not publicly available.

For each video sequence, the processing was first run on an initial group of 50 consecutive frames. If the modelling was successful, more frames were added in groups of 10 and the model reprocessed until the software failed to construct a point cloud. The last successful model was then considered as a subtransect and a new model was started with the next 50 frames. For each subtransect, the time at which the first ( $\left.t_{\text {start }}\right)$ and the last $\left(t_{\text {end }}\right)$ frames included in the model were recorded was listed and the likelihood of the camera trajectory was checked in the corresponding video. Impossible camera positions (i.e. lying in the ground or too far from the others) and obvious badly positioned SmartPoints (i.e. deep in the sediment or floating far above the substrate) were removed manually. After this cleaning procedure, the 3-D models were scaled to obtain the absolute distances in meters between any two 3-D SmartPoints. For the Antarctic deployments (dives $\mathrm{A}$ and $\mathrm{B})$ the frames $(N \geq 3$ per subtransect) selected were those that showed the laser dots most clearly on a flat surface. The known distance between the laser points was used to calibrate the distance between the two nearest 3-D SmartPoints. For dive $\mathrm{C}$ in Chile, the distance between the camera and the 


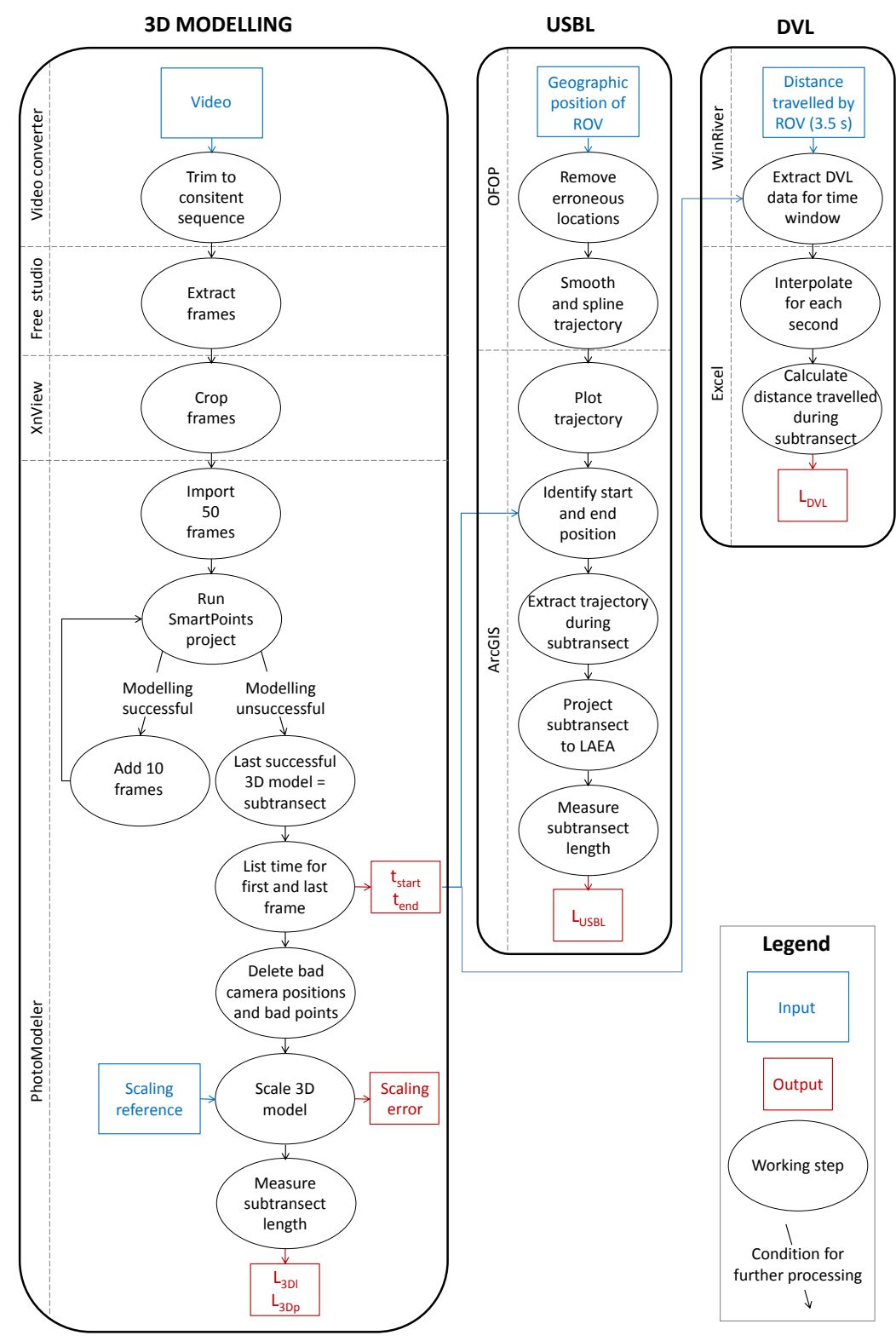

Fig. 1. Workflow for the determination of subtransect length through 3-D modelling, USBL navigation and DVL bottom tracking.

central point in the image, known from the echo sounder, was entered as a scaling reference every 10 images (Fig. 5).

When several scaling references are entered for one model, PhotoModeler applies an affine transformation to best fit all values and recalculates the dimensions of the references. A comparison between the dimensions estimated by PhotoModeler after scaling and the known size of the references provides a measure of the scaling error, expressed in percentage of the measured length. It includes both the 3-D SmartPoint positioning error by PhotoModeler and the error made while measuring the scaling references (laser points or echo sounder).
Finally, the linear subtransect length $\left(L_{3 \mathrm{Dl}}\right)$ was measured by considering the straight line between the central points in the first and last frames. The projected subtransect length ( $\left.L_{3 \mathrm{Dp}}\right)$ was obtained by measuring segments linking the central points of frame $n$ and frame $n+10$, moving from the first to the last frame in the 3-D model and thus following the substrate small-scale topography (Fig. 6).

All 3-D models and their dimensions are available at http: //doi.pangaea.de/10.1594/PANGAEA.803844. 


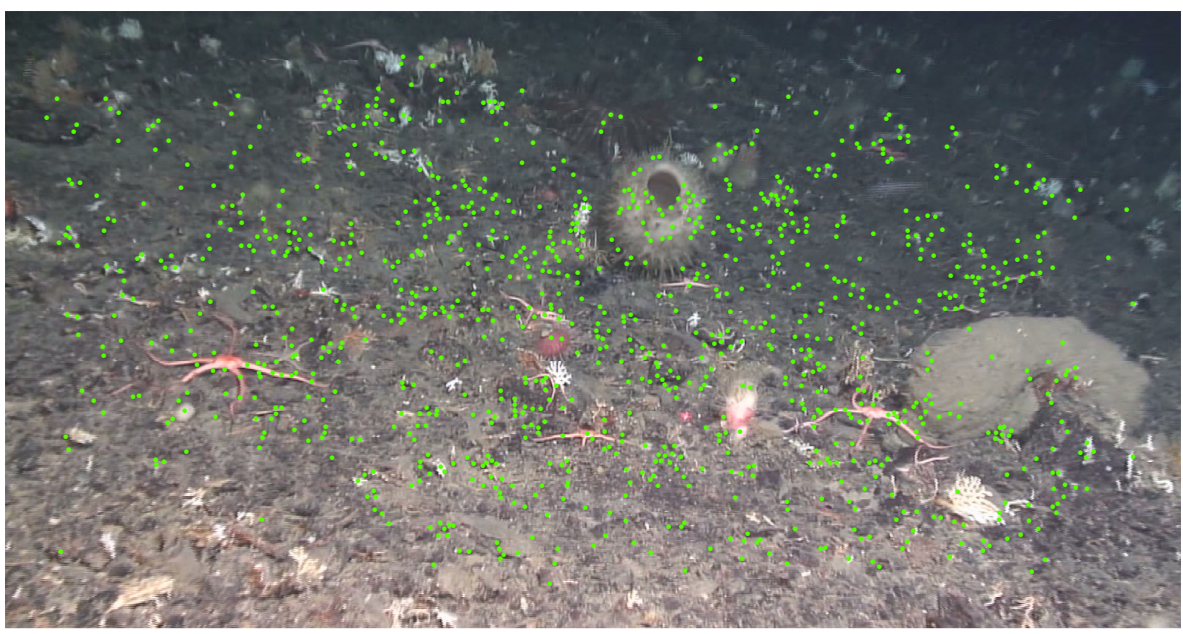

Fig. 2. SmartPoints (green dots) in PhotoModeler: automatic detection of natural features in a sample frame extracted from dive B.

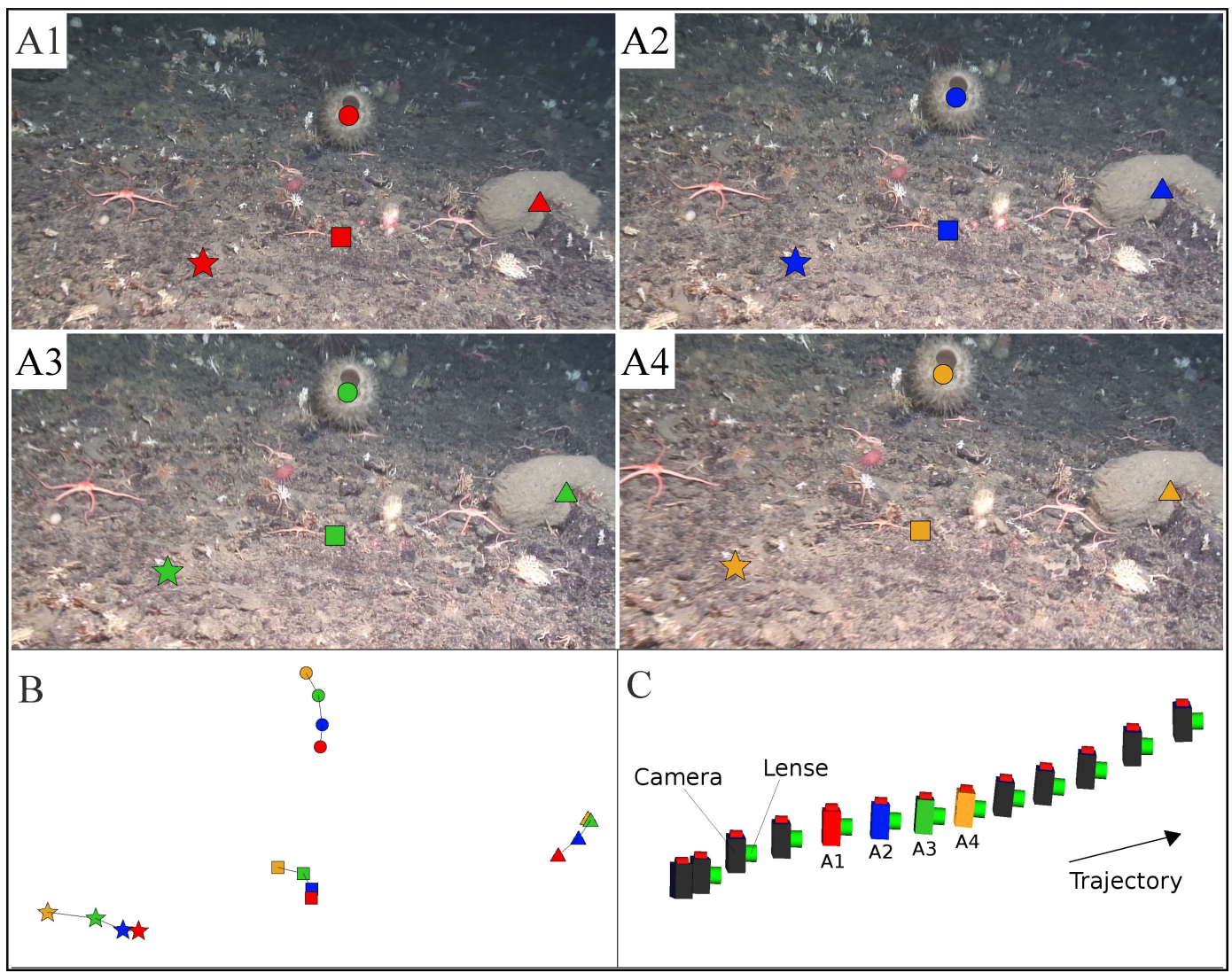

Fig. 3. SmartPoints matching and camera position reconstruction in PhotoModeler. (A1-4) Position of 4 SmartPoints identifying the same features on 4 consecutive frames. (B) Displacements of the 4 SmartPoints along the frames. (C) Reconstructed relative positions of the camera for the 4 previous frames within the subtransect.

\subsubsection{Underwater acoustic positioning}

The geographic position of the ROV obtained from the Posidonia USBL system was imported into OFOP for processing. Erroneous locations were identified by eye and removed.
The track was then smoothed using a floating mean algorithm taking the 20 nearest neighbours into account and the spline function was used to rebuild the position for every second. The smoothed trajectory was plotted into the software ArcGIS (ESRI) as a single polyline. Based on $t_{\text {start }}$ and $t_{\text {end }}$ from 


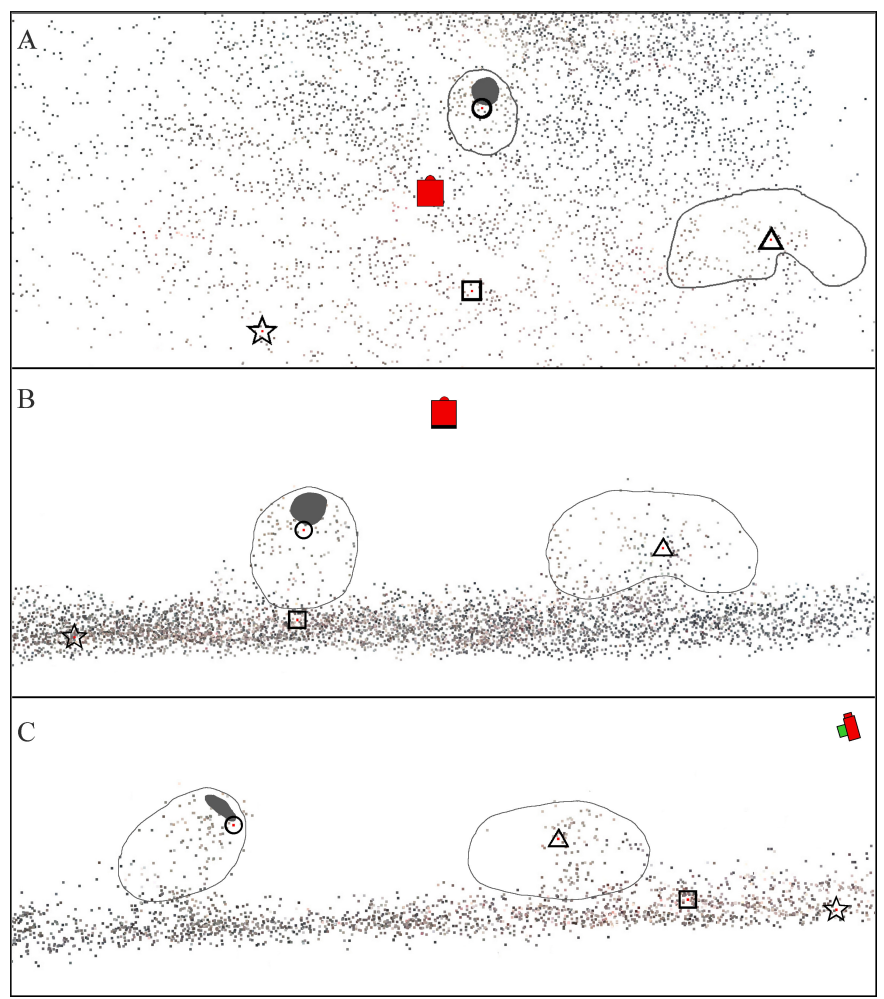

Fig. 4. 3-D SmartPoints cloud: the sponges visible in Figs. 2 and 3 are outlined. The same points are marked as in Fig. 3 and the relative orientation of the camera position A1 is shown in red. (A) View from the same angle as from camera position A1. (B) View from the same direction as camera position A1 but at bottom level. (C) View from the left side of camera position A1 at bottom level.

the 3-D models, the geographic position of the ROV at the beginning and at the end of each PhotoModeler subtransect was identified and the smoothed USBL trajectory was extracted between those two positions. The extracted track was then projected to a metric system to compute the distance travelled during the subtransect $\left(L_{\mathrm{USBL}}\right)$. The Lambert azimuthal equal area projection centred on the site was used, an equivalent coordinate system recommended for length measurements in the Antarctic Digital Database manual.

\subsubsection{Bottom tracking}

A Doppler velocity log acoustically tracks the velocity vector of a ROV relative to the substrate and computes the distance travelled by the vehicle. The DVL data was extracted for each subtransect from the WinRiver software (RDI) using the same time windows $\left(t_{\text {start }}\right.$ to $\left.t_{\text {end }}\right)$ for which 3-D models were created from the videos. As the time interval between two DVL measurements was $3.5 \mathrm{~s}$, a simple linear interpolation was realized to compute the data for every second and so calculate the distance travelled during each subtransect ( $\left.L_{\mathrm{DVL}}\right)$.

\section{Results}

\subsection{Performances}

\subsubsection{PhotoModeler}

For dive A in the Antarctic with a standard definition camera, fifty-two (52) subtransects were successfully reconstructed in 3-D (Table 2) with a mean scaling error of $4.7 \%$. The mean linear subtransect length $\left(L_{3 \mathrm{Dl}}\right)$ was $6.55 \mathrm{~m}$ from a total of $341 \mathrm{~m}$ modelled. The projected subtransect length $\left(L_{3 \mathrm{Dp}}\right)$ was different from $L_{3 \mathrm{Dl}}$ in only nine cases where a slight relief was observed along the subtransect. In those nine subtransects $L_{3 \mathrm{Dp}}$ was longer than $L_{3 \mathrm{DI}}$ by a maximum of $3 \%$.

For dive $\mathrm{B}$, located on the same site but with a high definition camera, seventy-one (71) subtransects were modelled (Table 2) and the scaling error was not significantly different from the one in dive A (Mann-Whitney rank sum test, $P=0.662)$. The linear subtransect length $\left(L_{3 \mathrm{DI}}\right)$ was, on average, $1.7 \mathrm{~m}$ longer than in dive A (Mann-Whitney rank sum test, $P=0.003$ ) and the total length modelled almost twice as long. Twenty-three (23) subtransects presented a slight relief for which $L_{3 \mathrm{Dp}}$ was measured as being longer than $L_{3 \mathrm{Dl}}$ by an average of $3 \%$. 


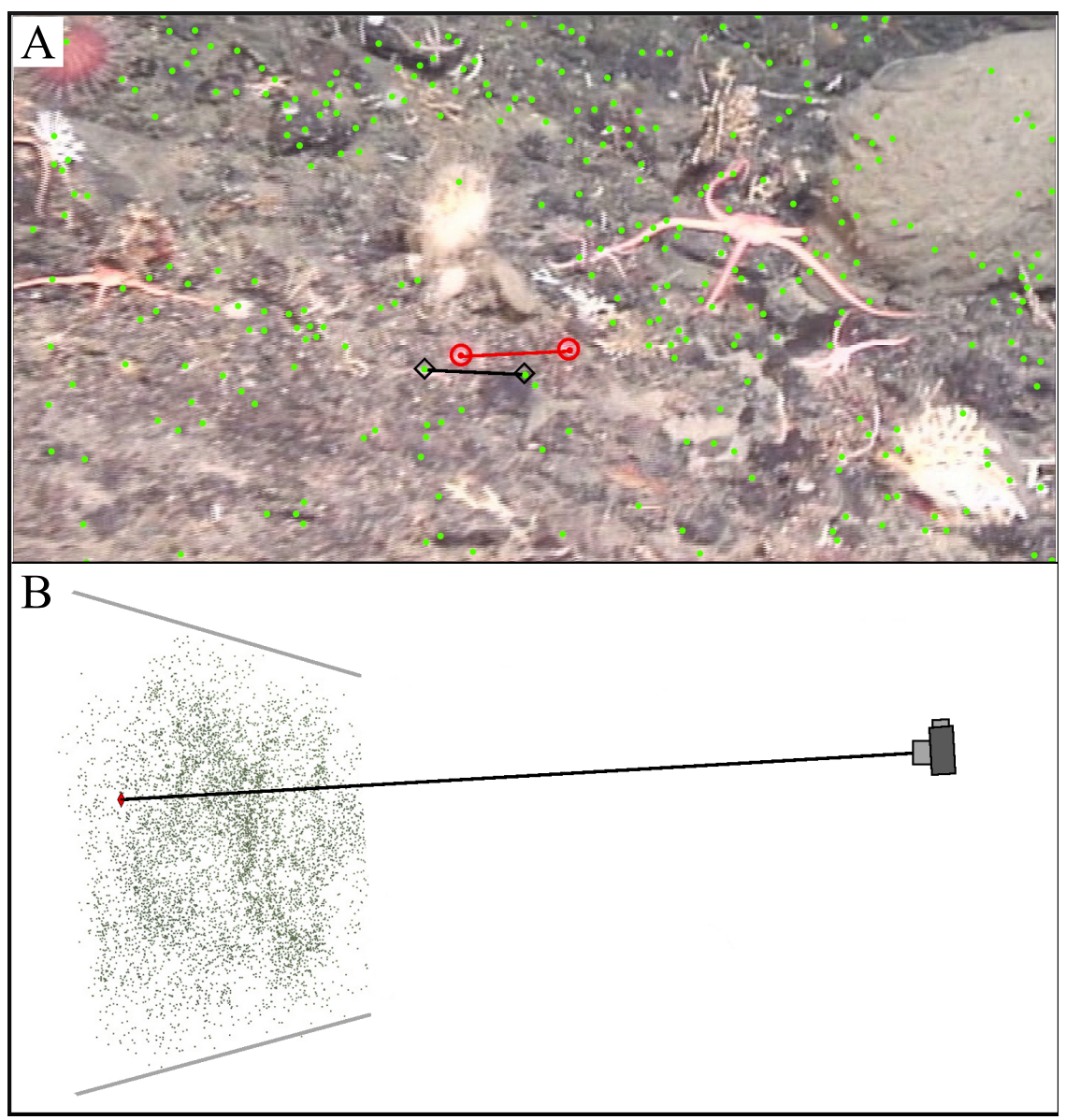

Fig. 5. Scaling of the 3-D models (A). Dive A and B (Antarctic): the distance between the laser points $(5 \mathrm{~cm}$, red line) is used to calculate the distance between the two nearest SmartPoints $(4.6 \mathrm{~cm}$, black line). (B) Dive C (Chile): the distance (1.9 m, black line) measured by the echo sounder between the camera and the central point (red dot) in the first frame (not represented here) is employed as scaling reference for the 3-D model (green dots, grey lines for perspective).

Table 2. Subtransects lengths computed from the 3-D models for the three dives.

\begin{tabular}{cccccc}
\hline Dive & $\begin{array}{c}\text { Number of } \\
\text { subtransects }\end{array}$ & $\begin{array}{c}\text { Calibration } \\
\text { error }(\%)\end{array}$ & $\begin{array}{c}\text { Type of } \\
\text { length }\end{array}$ & $\begin{array}{c}\text { Total } \\
\text { length }(\mathrm{m})\end{array}$ & $\begin{array}{c}\text { Mean } \\
\text { length }(\mathrm{m})\end{array}$ \\
\hline A & 52 & $4.7 \pm 3.4$ & $L_{3 \mathrm{Dl}}$ & 341 & $6.55 \pm 3.80$ \\
& \multirow{2}{*}{$\mathrm{*}$} & & $L_{3 \mathrm{Dp}}$ & 342 & $6.58 \pm 3.83$ \\
$\mathrm{~B}$ & \multirow{2}{*}{$4.7 \pm 2.8$} & $L_{3 \mathrm{Dl}}$ & 586 & $8.25 \pm 3.29$ \\
& \multirow{2}{*}{5} & \multirow{2}{*}{$10 \pm 6$} & $L_{3 \mathrm{Dp}}$ & 593 & $8.35 \pm 3.40$ \\
$\mathrm{C}$ & & & $L_{3 \mathrm{Dl}}$ & 182 & $3.31 \pm 1.58$ \\
& & & $L_{3 \mathrm{Dp}}$ & 213 & $3.87 \pm 1.93$ \\
\hline
\end{tabular}

Out of the sixty (60) 3-D models created in Chile (dive C), only fifty-five (55) could be scaled (Table 2) with an average scaling error of $10 \%$ of the length, more than twice as large as for dive A and B. The scaling error was positively correlated with the standard deviation of the distance to the substrate measured by the echo sounder during the subtransects (Pearson product moment correlation, correlation coefficient $=0.305, P=0.024)$. The reconstructed trajectories were in general shorter for those horizontal flights along the wall than for the line transects in the Antarctic as modelling often failed when the vehicle was moving too abruptly or when the slope changed too quickly due to the rough substrate. $L_{3 \mathrm{Dp}}$ was longer than $L_{3 \mathrm{Dl}}$ by $13 \%$, on average, for all but two subtransects where they were equal.

For one single subtransect, it took $1.5-6 \mathrm{~h}$ to pre-process the videos and go through the various steps necessary to 
Table 3. Computing time necessary to obtain subtransect length with the three different methods.

\begin{tabular}{lcccc}
\hline Method & Dive & $\begin{array}{c}\text { Time for the } \\
\text { entire dive } \\
\text { (hours) }\end{array}$ & $\begin{array}{c}\text { Time for one } \\
\text { subtransect } \\
\text { (minutes) }\end{array}$ & $\begin{array}{c}\text { Time for } \\
\text { one meter } \\
\text { (minutes) }\end{array}$ \\
\hline 3-D modelling & A & 88 & 101.5 & 15.5 \\
& B & 107 & 90.4 & 11.0 \\
Acoustic positioning & C & 80 & 87.3 & 26.4 \\
Bottom tracking & B & 1.5 & 1.3 & 0.2 \\
\hline
\end{tabular}

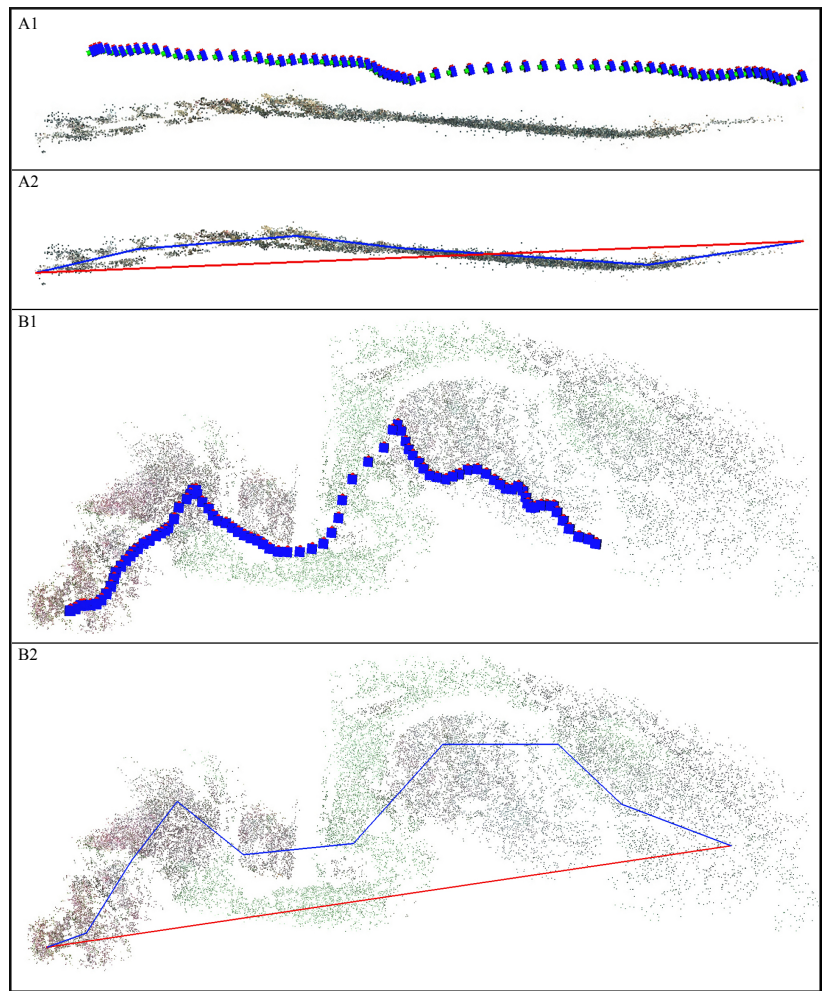

Fig. 6. 3-D models and subtransect length. (A) Example of a reconstructed ROV subtransect in the Antarctic seen in lateral view. (B) Example of a reconstructed ROV subtransect in Chile displayed in top-front view and showing the complex topography. (1) 3-D points cloud and camera positions. (2) 3-D points cloud, linear subtransect length $\left(L_{3 \mathrm{D} 1}\right.$, red line $)$ and projected subtransect length $\left(L_{3 \mathrm{Dp}}\right.$, blue segments).

obtain lengths from 3-D models with PhotoModeler. On average, this represented a computing time of $11-26 \mathrm{~min}$ to measure one meter of transect (Table 3).

\subsubsection{Underwater acoustic positioning}

The Posidonia underwater USBL positioning system yielded erratic results (Fig. 7), with consecutive positions sometimes up to $170 \mathrm{~m}$ apart. Removal of outliers and spline fitting the data allowed reasonable reconstructions of the vehicle's track. The mean distances between the OFOP smoothed trajectory and the raw Posidonia positions was $3.74 \pm 13.91 \mathrm{~m}$. The seventy-one (71) USBL subtransects corresponding to the 3-D models had an average length ( $L_{\mathrm{USBL}}$ ) of $6.45 \pm 2.79 \mathrm{~m}$ and a total length of $458 \mathrm{~m}$.

For a complete dive, the time needed to compute the length of all subtransects was about $1.5 \mathrm{~h}$, equivalent to a computing time of $12 \mathrm{~s}$ for one meter of transect (Table 3).

\subsubsection{Bottom tracking}

One third of the subtransects modelled in 3-D could not be measured by bottom tracking with the DVL because of missing data resulting from a too close range of the ROV $(<1.2 \mathrm{~m})$ or off-angle relative to the slope. Only measurements with less than $20 \%$ missing pings were included in the comparison, representing a number of thirty-seven (37) subtransects with an average length $\left(L_{\mathrm{DVL}}\right)$ of $3.48 \pm 1.72 \mathrm{~m}$ and a total length of $129 \mathrm{~m}$.

To obtain the length of one subtransect required a computing time between 11 and $37 \mathrm{~min}$ at an average speed of one meter every 7 min (Table 3 ).

\subsection{Comparison}

\subsubsection{3-D versus acoustic positioning}

For dive $\mathrm{B}, L_{\mathrm{USBL}}$ was significantly different from $L_{3 \mathrm{Dl}}$ (paired $t$ test, $P<0.001$ ). The linear subtransect length from PhotoModeler resulted in distances on average $20 \pm 22 \%$ longer than the acoustic navigation data. The methods agreement assessment strategy of Bland and Altman (1986) was applied by plotting the difference between the lengths obtained from 3-D modelling and acoustic positioning ( $L_{3 \mathrm{Dl}}-$ $\left.L_{\text {USBL }}\right)$ against the average between both methods $\left(\left(L_{3 \mathrm{DI}}+\right.\right.$ $L_{\text {USBL }}$ ) / 2) (Fig. 8). Despite large scatter, the difference tended to increase with increasing subtransect length (Pearson product moment correlation, correlation coefficient $=0.292, P=0.013$ ). Conducting the same tests with $L_{3 \text { Dp }}$ produced similar results. 


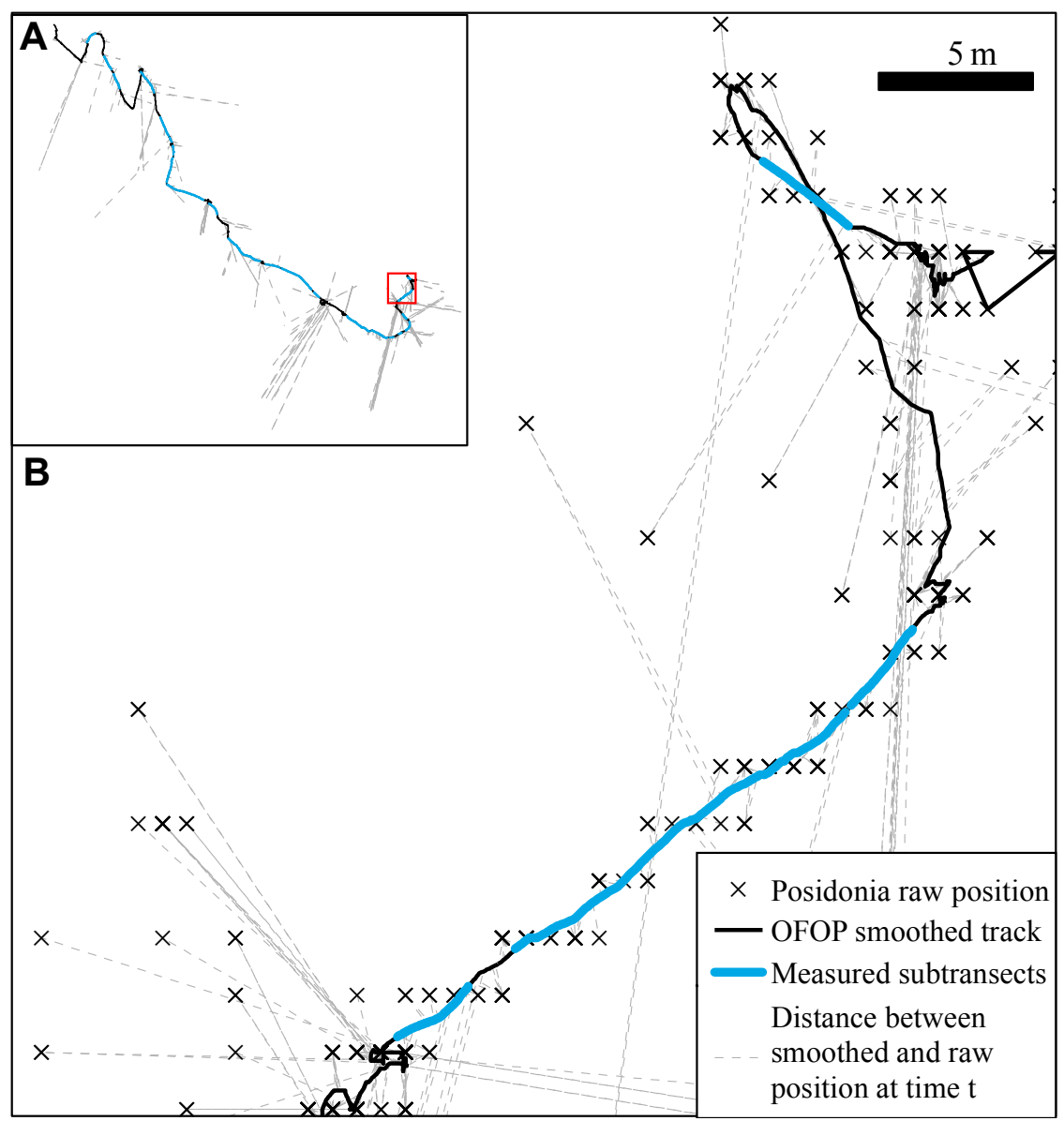

Fig. 7. (A) Overview showing the extent (red rectangle) of (B) high resolution detail of the ROV track during dive B (projection Lambert azimuthal equal area) highlighting the distance between the raw ROV positions from Posidonia and the OFOP smoothed trajectory.

\subsubsection{3-D versus bottom tracking}

No significant difference was detected between $L_{\mathrm{DVL}}$ and $L_{3 \mathrm{DI}}$ (paired $t$ test, $P=0.982$ ) but the test presented low power (0.05). As seen in Fig. 9, PhotoModeler linear subtransect lengths appeared comparable to DVL measurements with a mean difference around zero, yet showing a high scatter (standard deviation for $L_{\mathrm{DVL}}-L_{3 \mathrm{DI}}$ was $\pm 22 \%$ ).

The comparison of $L_{3 \mathrm{Dp}}$ and $L_{\mathrm{DVL}}$ identified a significant difference between the projected subtransect lengths in PhotoModeler and the DVL distances (Wilcoxon signed rank test, $P<0.001$ ). As shown in Fig. 10, $L_{3 \mathrm{Dp}}$ was clearly longer than $L_{\mathrm{DVL}}$ (mean difference $=14.85 \pm 20.84 \%$ of length) and the difference increased slightly with increasing distance (Pearson product moment correlation, correlation coefficient $=0.435, P=0.007$ ).

\section{Discussion}

\subsection{Performances}

\subsubsection{PhotoModeler}

The surface of the substrate was successfully modelled for several video sequences of all three ROV dives with PhotoModeler Scanner. It was thus shown that the method of 3-D subtransect reconstruction aiming at distance measurements is applicable for both vertical and oblique camera orientations. As the scaling error for the models was not significantly different between dive A and B in the Antarctic and represented less than $5 \%$ of the length, it seems that neither the video quality (standard or high definition) nor the length of the scaling references biased the accuracy of the 3-D models. Comparable quantitative data from dive A and B could be computed from PhotoModeler data as the surface of the subtransects was assessed using the same method. This was not possible with traditional methods of survey area determination as navigation was missing for dive A. For those two deployments, two parallel lasers placed at respective distances 


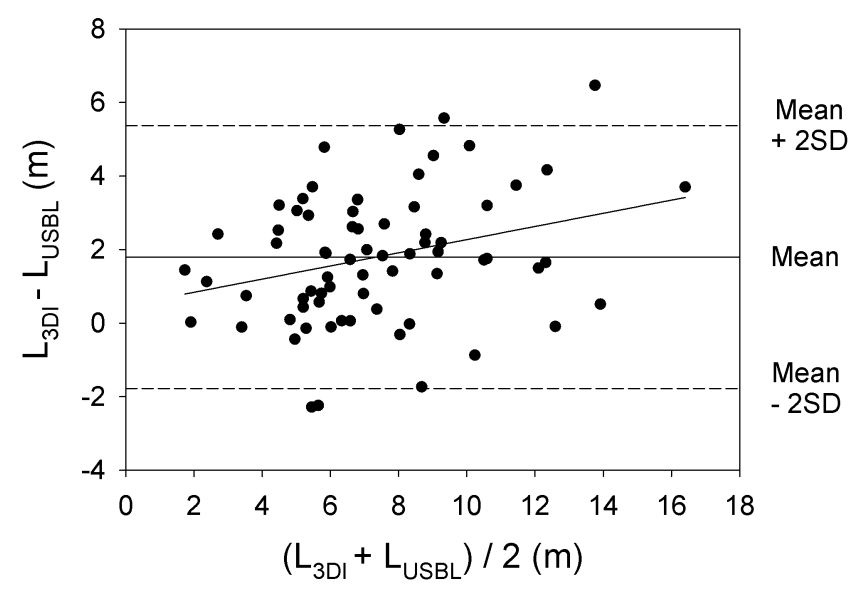

Fig. 8. Bland and Altman plot of difference against mean for the subtransect lengths measured from 3-D models $\left(L_{3 \mathrm{D} 1}\right)$ and from underwater navigation $\left(L_{\mathrm{USBL}}\right)$.

of 20 and $5 \mathrm{~cm}$ from each other were projected on a relatively flat bottom so that the scale remained mostly unaltered and constantly visible directly in the frames integrated into the model. The difference in the subtransect lengths between dives $\mathrm{A}$ and $\mathrm{B}$ can be explained by the higher altitude and speed with which the ROV was flown during dive A. These conditions increased the difficulty for PhotoModeler to follow up features displacement. In Chile (dive C), the use of the echo sounder as a scaling reference in a rough stony habitat yielded a scaling error twice as large as for dive A and B. This error increases when the scale itself is not properly measured. The echo sounder was sometimes disturbed by the presence of superimposed objects positioned at various distances in its field of view. Moreover, its data were recorded independently of the videos, and a delay of only 1s in time synchronization could mean a great change in the distance to the substrate. The standard deviation of the distance to the substrate reflects the amount of change in the distance from the camera to the substrate, i.e. the roughness of the small-scale topography. It is thus not surprising that the scaling error was positively correlated to the variability of the distance to the substrate as a rougher topography would mean a higher measurement inaccuracy for the scale. Lasers would not have performed better than the echo sounder as they are often not visible in rough habitats and their projection becomes distorted (Karpov et al., 2006). Furthermore, piloting was influenced by the topography, leading to shorter subtransects modelled in Chile due to abrupt camera movements. Overall, the accuracy of the models presented in this study was acceptable and comparable to results obtained from perspective grids (Smith and Hamilton, 1983; Kocak et al., 2004). The distortion of the reference scales due to substrate roughness in Chile was identified as the main source of imprecision.

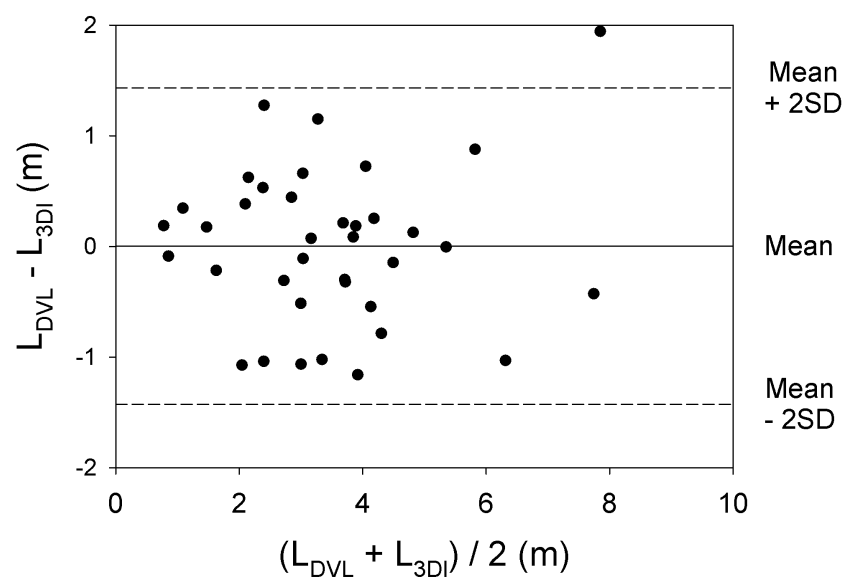

Fig. 9. Bland and Altman plot of difference against mean for the subtransect length measured from bottom tracking $\left(L_{\mathrm{DVL}}\right)$ and the linear subtransect length in PhotoModeler $\left(L_{3 \mathrm{Dl}}\right)$.

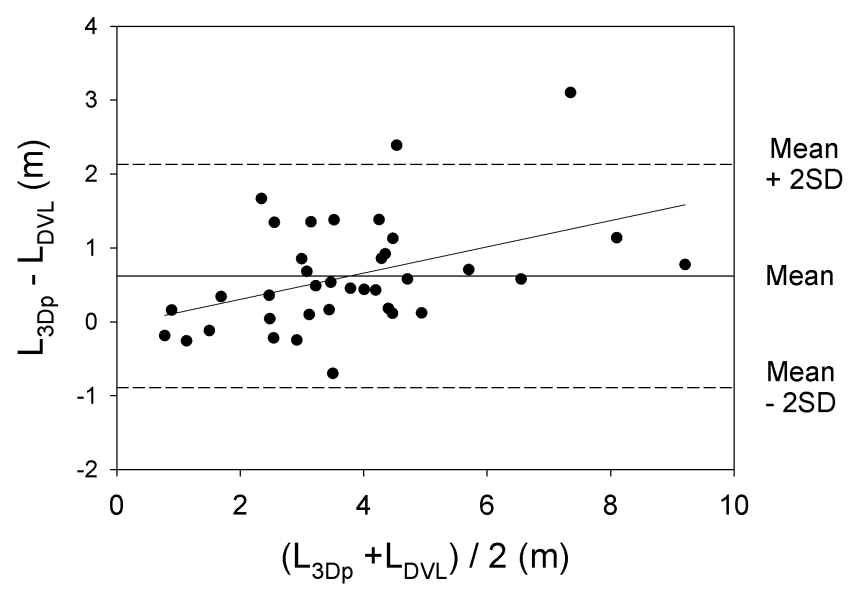

Fig. 10. Bland and Altman plot of difference against mean for the projected subtransect length in PhotoModeler $\left(L_{3 \mathrm{Dp}}\right)$ and the subtransect length measured from bottom tracking $\left(L_{\mathrm{DVL}}\right)$.

The performance of PhotoModeler for subtransect length measurements was tested. In a similar manner, the width could be determined from the 3-D models. After export of the point cloud to computer-aided design software even the area of the entire subtransect or of given surfaces could be directly computed (Bythell et al., 2001). In this study, modelling was realized with frames extracted from videos but the software is also able to work with overlapping still pictures (Bythell et al., 2001; Green et al., 2002; de Bruyn et al., 2009). The processing requires identifiable features on the images and the sandy/rocky habitats in the Antarctic and Chile offered several such features. In contrast, the modelling of muddy substrate could be more difficult due to featureless or smooth surfaces (Green and Gainsford, 2003). Calibrating 
the camera could improve the accuracy of the data ciphered from 3-D models (Ewins and Pilgrim, 1997; Bythell et al., 2001; Cocito et al., 2003; Green and Gainsford, 2003). However, calibration requires direct access to the camera, is usually performed in shallow water and can be affected by depth (Shortis et al., 2008). Reference targets of known size could also facilitate scaling (Green et al., 2002), especially in complex habitat structures where laser projections are distorted and echo sounders disturbed by the topography. Nonetheless the deployment of objects along a transect is a long and difficult task in deep environments where sledges and ROVs are usually set. Deploying stereo cameras could also be a solution as the distance between both cameras could be used as scaling reference (Shortis et al., 2008; Althaus et al., 2009; Beall et al., 2010).

\subsubsection{Underwater acoustic positioning}

The Posidonia USBL system used during dive $\mathrm{B}$ revealed a positioning accuracy far worse than the $0.3 \%$ of distance expected from the instrument specification $(60 \mathrm{~cm}$ on a $200 \mathrm{~m}$ deep site). Underwater acoustic devices can be affected either by signal disturbances or sound velocity (Gamroth et al., 2011). Therefore, we assume that the system was disturbed by stratification (halocline), the presence of ice crystals in the water and a rather low sound velocity of about $1440 \mathrm{~m} \mathrm{~s}^{-1}$. Compared to distances between bathymetric features known from charts USBL navigation revealed more accuracy in shallow water $(<30 \mathrm{~m}$ ) (Karpov et al., 2006) but yielded similar instabilities in deeper water $(>600 \mathrm{~m})$ (Althaus et al., 2009). Moreover, in Chile, the Micronav USBL system almost completely failed to record the ROV position in a steep channel setting with vertical walls which act both as reflective surfaces and obstacles for the acoustic signal. Distance measurements from underwater trajectories can become more accurate by increasing the length of the subtransect (Barry and Baxter, 1993; Karpov et al., 2006). However video transects cannot always be exploited in their entire length due to bad quality sequences. New technologies couple USBL data with DVL speed measurements for better navigation (Kinsey and Whitcomb, 2004; Kocak et al., 2004; Dolan et al., 2008). Likewise, long baseline can be employed for precise positioning (Parry et al., 2003) although it implies the deployment of an additional system on the site (Pilgrim et al., 2000).

\subsubsection{Bottom tracking}

A considerable amount of data from the DVL was not usable, probably because the vehicle flew too close to the substrate (Pinkard et al., 2005). Nonetheless it has been proven that DVL bottom tracking can be as accurate as GPS positioning for a ship (Snyder, 2010) and more precise than USBL for a ROV (Pinkard et al., 2005). The performance of the DVL could be improved by coupling it to the attitude sensor of the ROV (Kinsey et al., 2006; Snyder, 2010). In this study, these inaccuracies were minimized by keeping the heading as constant as possible and by the ROV's automatic stabilization of depth, tilt and roll.

\subsection{Comparison}

While using underwater acoustic navigation data to calculate the distance travelled, even with an appropriate coordinate system, the trajectory is usually projected on a flat surface unless a bathymetric model is integrated. This explains why the distances ciphered from USBL positioning were shorter than those computed from 3-D models (Barry and Baxter, 1993). Moreover, positioning inaccuracies in Posidonia and post-processing in OFOP influenced the USBL subtransect lengths. Smoothing, i.e. removing small-scale jitter and loops from the track, is equivalent to shortening the ROV track (ultimately to a straight line). In contrast, the 3-D method integrated the tiniest movements. The difference between both lengths is correlated to the distance measured as the number of small deviations from the straight line increases on a longer path.

Bottom tracking with a DVL uses the structure of the substrate to compute the straight line distance travelled by the vehicle but does not project the path on the topography. Hence such data were comparable to the linear subtransect length obtained with PhotoModeler in Chile. However these results must be considered carefully, due to the low power of the test. The high variability of the difference values between both methods suggests an underlying mismatch probably due to the weaknesses of the DVL data.

Substrate relief and roughness cannot be ignored as they have an ecological significance (e.g. Wilson et al., 2007; Gratwicke and Speight, 2005) but they lead to more challenging analysis. PhotoModeler allows the user to take the small-scale topography into consideration, for instance by measuring a projected subtransect length. This measure was, as expected, longer than the linear subtransect length and the DVL bottom track every time the bottom presented some relief or 3-D structure. Moreover, the difference between the DVL measurements and the projected subtransect length obtained with PhotoModeler were correlated to the distance measured. As in acoustic positioning, this can also be explained by the amount of deviation from the straight line increasing on a longer path. However, the precision used for the projection must be standardized as the subtransect length could be extended up to infinity by increasing the resolution (Mandelbrot, 1967). The main advantage of 3-D modelling is that measurements can be performed on the actual substrate topography (Shortis et al., 2008) taking the slope and small-scale relief into account and related directly to objects and surfaces visible in the videos. Used in combination with an endoscopic camera (Wunsch and Richter, 1998), PhotoModeler could allow the mapping of cryptic habitats such as cracks and crevices in coral reefs (Richter et al., 2001). 
For the estimation of substrate area needed for density studies, 3-D modelling seems much more suitable than DVL and USBL data, especially in high-relief habitats. Nevertheless the processing in PhotoModeler is extremely time consuming (see also Cocito et al., 2003). Obtaining subtransect lengths from 3D models took us twice as long as from bottom tracking and lasted up to 130 times longer than distance measurements from the acoustic navigation system.

In terms of data representation, trajectories from an underwater positioning system can be directly mapped, which is an advantage. The movements over ground recorded by a DVL are displayed in real time, allowing distance measurements during the deployment. 3-D models give an insight into the structure of the substrate, a significant ecological factor. Besides, PhotoModeler offers an option for geo-referencing and export to other software for further processing.

\subsection{Conclusion}

In summary, 3-D modelling is a solution to compare quantitative data extracted from several underwater video transects. Applicable on a variety of set-ups, it is an alternative to compute subtransect dimensions when more traditional methods cannot be employed. For example, image scaling, underwater acoustic positioning or DVL bottom tracking may fail due to unsuitable camera set-ups, unavailability of instruments, inaccurate measurements and difficult environmental conditions such as high relief. One of the main advantages of 3-D reconstruction is that it relates directly to the surfaces and objects seen in the images. In the case of rough substrates, it is the first step to accurately measure areas considering the actual topography. Nevertheless, scaling the model is a sensitive issue, especially in habitats showing high structural complexity, and the accuracy of the measurements will greatly depend upon it. At the present time, the disadvantage of 3-D processing in PhotoModeler is the decidedly time-consuming procedure. Whether or not 3-D modelling should be used depends on the other methods applicable for determining the surface surveyed, the topography of the site, and on the goal and scale of the study.

Acknowledgements. We would like to acknowledge Marum, University of Bremen; the Sven Lovén Centre, University of Gothenburg; and the Department of Bentho-Pelagic Processes, Alfred Wegener Institute, for providing ROVs and video footage; and to the Endesa Fundation Huinay for their logistic support in Chile. We thank W. Dimmler (Fielax, Bremerhaven), Tomas Lundälv (University of Gothenburg, Sweden) and Claudio Richter (Alfred Wegener Institute, Bremerhaven) for assistance in piloting the ROVs. Thanks are due to Julian Gutt for providing video material from ANT-XXIII/8 and to Sandra Maier for her help in the creation of the 3-D models. We also acknowledge Kerstin Jerosch, Gertraud Schmidt, Ruth Alheit, Nils Owsianowski, Claudio Richter and three anonymous reviewers for their contributions to improving this manuscript. Many thanks go to the captains, crew and scientists on our expeditions in the Antarctic (R/V Polarstern) and Chilean
Patagonia (M/V Explorador). Funding was provided by a $\mathrm{BmBF}$ project (Ökologie von Hydrokorallenriffe im Flachwasser der Patagonischen Fjorde Chiles, Grant \#CHL08/001) and the Alfred Wegener Institute (PACES T1.4 and 1.6).

Edited by: O. Zielinski

\section{References}

Althaus, F., Williams, A., Schlacher, T. A., Kloser, R. J., Green, M. A., Barker, B. A., Bax, N. J., Brodie, P., and SchlacherHoenlinger, M. A.: Impacts of bottom trawling on deep-coral ecosystems of seamounts are long-lasting, Mar. Ecol.-Prog. Ser., 397, 279-294, doi:10.3354/meps08248, 2009.

Amado-Filho, G. M., Pereira-Filho, G. H., Bahia, R. G., Abrantes, D. P., Veras, P. C., and Matheus, Z.: Occurrence and distribution of rhodolith beds on the Fernando de Noronha Archipelago of Brazil, Aquat. Bot., 101, 41-45, doi:10.1016/j.aquabot.2012.03.016, 2012.

Ambrose, W. G., von Quillfeldt, C., Clough, L. M., Tilney, P. V. R., and Tucker, T.: The sub-ice algal community in the Chukchi sea: large- and small-scale patterns of abundance based on images from a remotely operated vehicle, Polar Biol., 28, 784-795, doi:10.1007/s00300-005-0002-8, 2005.

Anderson, T. J. and Yoklavich, M. M.: Multiscale habitat associations of deepwater demersal fishes off central California, Fish. B NOAA, 105, 168-179, http://fishbull.noaa.gov/1052/anderson. pdf, 2007.

Auster, P. J., Stewart, L. L., and Sprunk, H.: Scientific imaging with ROVs: tools and techniques, Mar. Technol. Soc. J., 23, 16-20, 1989.

Baker, K. D., Haedrich, R. L., Snelgrove, P. V. R., Wareham, V. E., Edinger, E. N., and Gilkinson, K. D.: Small-scale patterns of deep-sea fish distributions and assemblages of the Grand Banks, Newfoundland continental slope, Deep-Sea Res. Pt. I, 65, 171188, doi:10.1016/j.dsr.2012.03.012, 2012a.

Baker, K. D., Wareham, V. E., Snelgrove, P. V. R., Haedrich, R. L., Fifield, D. A., Edinger, E. N., and Gilkinson, K. D.: Distributional patterns of deep-sea coral assemblages in three submarine canyons off Newfoundland, Canada, Mar. Ecol.-Prog. Ser., 445, 235-249, doi:10.3354/meps09448, 2012b.

Barry, J. P. and Baxter, C. H.: Survey design considerations for deep-sea benthic communities using ROVs, Mar. Technol. Soc. J., 26, 20-26, 1993.

Beall, C., Lawrence, B. J., Ila, V., and Dellaert, F.: 3D reconstruction of underwater structures, in: The IEEE/RJS 2010 International Conference on Intelligent Robots and Systems (IROS2010), Taipei, Taiwan, 18-22 October 2010, 4418-4423, doi:10.1109/IROS.2010.5649213, 2010.

Bland, J. M. and Altman, D. G.: Statistical method for assessing agreement between two methods of clinical measurement, Lancet, 327, 307-310, doi:10.1016/S0140-6736(86)90837-8, 1986.

Bonin, F., Burguera, A., and Oliver, G.: Imaging systems for advanced underwater vehicles, J. Marit. Res., 3, 65-86, 2011.

Brandou, V. and Allais, A. G. and Perrier, M. and Malis, E. and Rives, P. and Sarrazin, J. and Sarradin, P. M.: 3D reconstruction of natural underwater scenes using the stereo- 
vision system IRIS, in: Proceedings of OCEANS'07 IEEE Conference, Aberdeen, Scotland, 18-21 June 2007, 1-6, doi:10.1109/OCEANSE.2007.4302315, 2005.

Bythell, J. C., Pan, P., and Lee, J.: Three-dimensional morphometric measurements of reef corals using underwater photogrammetry techniques, Coral Reefs, 20, 193-199, doi:10.1007/s003380100157, 2001.

Carleton, J. H. and Done, T. J.: Quantitative video sampling of coral reef benthos: large-scale application, Coral Reefs, 14, 35-46, doi:10.1007/BF00304070, 1995.

Chevaldonné, P. and Jollivet, D.: Videoscopic study of deep-sea hydrothermal vent alvinellid polychaete populations: biomass estimation and behaviour, Mar. Ecol.-Prog. Ser., 95, 251-262, doi:10.3354/meps095251, 1993.

Chu, J. W. F. and Leys, S. P.: High resolution mapping of community structure in three glass sponge reefs (Porifera, Hexactinellida), Mar. Ecol.-Prog. Ser., 417, 97-113, doi:10.3354/meps08794, 2010.

Cocito, S., Sgorbini, S., Peirano, A., and Valle, M.: 3D reconstruction of biological objects using underwater video technique and image processing, J. Exp. Mar. Biol. Ecol., 297, 57-70, doi:10.1016/S0022-0981(03)00369-1, 2003.

Cranmer, T. L., Ruhl, H. A., Baldwin, R. J., and Kaufmann, R. S.: Spatial and temporal variation in the abundance, distribution and population structure of epibenthic megafauna in Port Foster, Deception Island, Deep-Sea Res. Pt. II, 50, 1821-1842, doi:10.1016/S0967-0645(03)00093-6, 2003.

Cuvelier, D., Sarrazin, J., Colaco, A., Copley, J., Desbruyères, D., Glover, A. G., Tyler, P., and Santos, S. R.: Distribution and spatial variation of hydrothermal faunal assemblages at Lucky Strike (Mid-Atlantic Ridge) revealed by high-resolution video image analysis, Deep-Sea Res. Pt. I, 56, 2026-2040, doi:10.1016/j.dsr.2009.06.006, 2009.

de Bruyn, P. J. N., Bester, M. N., Carlini, A. R., and Oosthuizen, W. C.: How to weigh an elephant seal with one finger: a simple three-dimensional photogrammetric application, Aquat. Biol., 5, 31-39, doi:10.3354/ab00135, 2009.

Dolan, M. F. J., Grehan, A. J., Guinan, J. C., and Brown, C.: Modelling the local distribution of cold-water corals in relation to bathymetric variables: adding spatial context to deep-sea video data, Deep-Sea Res. Pt. I, 55, 1564-1579, doi:10.1016/j.dsr.2008.06.010, 2008.

Dowdeswell, J. A., Evans, J., Mugford, R., Griffiths, G., McPhail, S., Millard, N., Stevenson, P., Brandon, M. A., Banks, C., Heywood, K. J., Price, M. R., Dodd, P. A., Jenkins, A., Nicholls, K. W., Hayes, D., Abrahamsen, E. P., Tyler, P., Bett, B., Jones, D., Wadhams, P., Wilkinson, J. P., Stansfield, K., and Ackley, S.: Autonomous underwater vehicles (AUVs) and investigations of the ice-ocean interface in Antarctic and Arctic waters, J. Glaciol., 54, 661-672, doi:10.3189/002214308786570773, 2008.

Ewins, N. J. and Pilgrim, D. A.: The evaluation of PhotoModeler for use under water, in: The Fourth Underwater Science Symposium: Proceedings, Newcastle upon Tyne, UK, 19-20 November 1997, 135-145, 1997.

Gamroth, E., Kennedy, J., and Bradley, C.: Design and testing of an acoustic ranging technique applicable for an underwater positioning system, Underwater Technol., 29, 183-193, doi:10.3723/ut.29.183, 2011.
Garcia, R., Battle, J., and Cufi, X.: Positioning an underwater vehicle through image mosaicking, in: Proceedings of the 2001 IEEE International Conference on Robotics \& Automation, Seoul, Korea, 21-25 May 2001, 2779-2784, doi:10.1109/ROBOT.2001.933043, 2001.

Gratwicke, B. and Speight, M. R.: The relationship between fish species richness, abundance and habitat complexity in a range of shallow tropical marine habitats, J. Fish Biol., 66, 650-667, doi:10.1111/j.0022-1112.2005.00629.x, 2005.

Green, J. and Gainsford, M.: Evaluation of underwater surveying techniques, Int. J. Naut. Archaeol., 32, 252-261, doi:10.1016/j.ijna.2003.08.007, 2003.

Green, J., Matthews, S., and Turanli, T.: Underwater archaeological surveying using PhotoModeler, VirtualMapper: different applications for different problems, Int. J. Naut. Archaeol., 31, 283292, doi:10.1006/ijna.2002.1041, 2002.

Guinan, J., Grehan, A. J., Dolan, M. F. J., and Brown, C.: Quantifying relationships between video observations of cold-water coral cover and seafloor features in Rockall Trough, west of Ireland, Mar. Ecol.-Prog. Ser., 375, 125-138, doi:10.3354/meps07739, 2009.

Gutt, J. and Starmans, A.: Quantification of iceberg impact and benthic recolonisation patterns in the Weddell Sea (Antarctica), Polar Biol., 24, 615-619, doi:10.1007/s003000100263, 2001.

Huetten, E. and Greinert, J.: Software controlled guidance, recording and post-processing of seafloor observations by ROV and other towed devices: The software package OFOP, Geophys. Res. Abstr., 10, EGU2008-A-03088, 2008.

Jerosch, K., Lüdtke, A., Schlüter, M., and Ioannidis, G. T.: Automatic content-based analysis of georeferenced image data: Detection of Beggiatoa mats in seafloor video mosaics from the Håkon Mosby Mud Volcano, Comput. Geosci., 33, 202-218, doi:10.1016/j.cageo.2006.06.014, 2007.

Jones, D. O. B., Hudson, I. R., and Bett, B. J.: Effects of physical disturbance on the cold-water megafaunal communities of the Faroe-Shetland Channel, Mar. Ecol.-Prog. Ser., 319, 43-54, doi:10.3354/meps319043, 2006.

Jones, D. O. B., Bett, B. J., Wynn, R. B., and Masson, D. G.: The use of towed camera platforms in deep-water science, Underwater Technol., 28, 41-50, doi:10.3723/ut.28.041, 2009.

Karpov, K. A., Lauermann, A., Bergen, M., and Prall, M.: Accuracy and precision of measurements of transect length and width made with a remotely operated vehicle, Mar. Technol. Soc. J., 40, 79 85, doi:10.4031/002533206787353196, 2006.

Karpov, K. A., Bergen, M., and Geibel, J. J.: Monitoring fish in California Channel Islands marine protected areas with a remotely operated vehicle: the first five years, Mar. Ecol.-Prog. Ser., 453, 159-172, doi:10.3354/meps09629, 2012.

Kinsey, J. C. and Whitcomb, L. L.: Preliminary field experience with the DVLNAV integrated navigation system for oceanographic submersibles, Control Eng. Pract., 12, 1541-1549, doi:10.1016/j.conengprac.2003.12.010, 2004.

Kinsey, J. C., Eustice, R. M., and Whitcomb, L. L.: A survey of underwater vehicle navigation: recent advances and new challenges, in: Proceedings of the IFAC Conference of Manoeuvering and Control of Marine Craft, Lisbon, Portugal, 20-22 September 2006, 2006.

Kocak, D. M., Jagielo, T. H., Wallace, F., and Kloske, J.: Remote sensing using laser projection photogrammetry 
for underwater surveys, in: 2004 IEEE International Geoscience and Remote Sensing Symposium Proceedings (IGARSS 2004), Anchorage, Alaska, 20-24 September 2004, 1451-1454, doi:10.1109/IGARSS.2004.1368693, 2004.

Kocak, D. M., Dalgleish, F. R., Caimi, F. M., and Schechner, Y. Y.: A focus on recent developments and trends in underwater imaging, Mar. Technol. Soc. J., 42, 52-67, 2008.

Laudien, J. and Orchard, J. B.: The significance of depth and substratum incline for the structure of a hard bottom sublittoral community in glacial Kongsfjorden (Svalbard, Arctic) an underwater imagery approach, Polar Biol., 35, 1057-1072, doi:10.1007/s00300-011-1153-4, 2012.

Lindsay, D. J., Yoshida, H., Uemura, T., Yamamoto, H., Ishibashi, S., Nishikawa, J., Reimer, J. D., Beaman, R. J., Fitzpatrick, R., Fujikura, K., and Maruyama, T.: The untethered remotely operated vehicle PICASSO-1 and its deployment from chartered dive vessels for deep sea surveys off Okinawa, Japan, and Osprey Reef, Coral Sea, Australia, Mar. Technol. Soc. J., 46, 20-32, doi:10.4031/MTSJ.46.4.3, 2012.

Mandelbrot, B.: How long is the coast of Britain? Statistical selfsimilarity and fractional dimension, Science, 156, 636-638, doi:10.1126/science.156.3775.636, 1967.

Parry, D. M., Nickell, L. A., Kendall, M. A., Burrows, M. T., Pilgrim, D. A., and Jones, M. B.: Comparison of abundance and spatial distribution of burrowing megafauna from diver and remotely operated vehicle observations, Mar. Ecol.-Prog. Ser., 244, 89-93, doi:10.3354/meps244089, 2002.

Parry, D. M., Kendall, M. A., Pilgrim, D. A., and Jones, M. B.: Identification of patch structure within marine benthic landscapes using a remotely operated vehicle, J. Exp. Mar. Biol. Ecol., 285286, 497-511, doi:10.1016/S0022-0981(02)00546-4, 2003.

Patterson, W. F. I., Dance, M. A., and Addis, D. T.: Development of a remotely operated vehicle based methodology to estimate fish community structure at artificial reef sites in the northern Gulf of Mexico, in: Proceedings of the 61st Gulf and Caribbean Fisheries Institute, Gosier, Guadeloupe, French West Indies, 1014 November 2008, 263-270, 2009.

Pilgrim, D. A., Parry, D. M., Jones, M. B., and Kendall, M. A.: ROV image scaling with laser spot patterns, Underwater Technol., 24, 93-103, doi:10.3723/175605400783259684, 2000.

Pinkard, D. R., Kocak, D. M., and Butler, J. L.: Use of a video and laser system to quantify transect area for remotely operated vehicle (ROV) rockfish and abalone surveys, in: Oceans 2005 Proceedings of MTS/IEEE Conference, Washington DC, USA, 18-23 September 2005, 2824-2829, doi:10.1109/OCEANS.2005.1640203, 2005.

Pizarro, O. and Eustice, R. and Singh, H.: Large area 3D reconstruction from underwater surveys, in: Oceans 2004. Proceeding of MTTS/IEEE TECHNO-OCEAN '04 Conference, Kobe, Japan, 9-12 November 2004, 2, 678-687 doi:10.1109/OCEANS.2004.1405509, 2004.

Pollio, J.: Applications of underwater photogrammetry, Mar. Technol. Soc. J., 40, 34-51, doi:10.4031/002533206787353411, 1969.

Post, A. L., O’Brien, P. E., Beaman, R. J., Riddle, M. J., and De Santis, L.: Physical control on deep water coral communities on the George V Land slope, East Antarctica, Antarct. Sci., 22, 371378, doi:10.1017/S0954102010000180, 2010.
Post, A. L., Beaman, R. J., O’Brien, P. E., Eléaume, M., and Riddle, M. J.: Community structure and benthic habitats across the George V Shelf, East Antarctica: trends through space and time, Deep-Sea Res. Pt. II, 58, 105-118, doi:10.1016/j.dsr2.2010.05.020, 2011.

Richter, C., Wunsch, M., Rasheed, M., Kötter, I., and Badran, M. I.: Endoscopic exploration of Red Sea coral reefs reveals dense populations of cavity-dwelling sponges, Nature, 413, 726-730, doi:10.1038/35099547, 2001.

Ruhl, H. A.: Abundance and size distribution dynamics of abyssal epibenthic megafauna in the Northeast Pacific, Ecology, 88, 1250-1262, doi:10.1890/06-0890, 2007.

Schettini, R. and Corchs, S.: Underwater image processing: state of the art of restoration and image enhancement methods, EURASIP J. Adv. Sig. Pr., 2010, 746052, doi:10.1155/2010/746052, 2010.

Sedlazeck, A., Köser, K., and Koch, R.: 3D reconstruction based on underwater video from ROV Kiel 6000 considering underwater imaging conditions, in: Proceedings of the IEEE Oceans 2009 Conference, Bremen, Germany, 11-14 May 2010, 1-10, doi:10.1109/OCEANSE.2009.5278305, 2009.

Shortis, M. R., Seager, J. W., Williams, A., Barker, B. A., and Sherlock, M.: Using stereo-video for deep water benthic habitat surveys, Mar. Technol. Soc. J., 42, 28-37, doi:10.4031/002533208787157624, 2008.

Sievers, J. and Bennat, H.: Reference systems of maps and geographic information systems of Antarctica, Antarct. Sci., 1, 351362, 1989.

Smith, C. R. and Hamilton, S. C.: Epibenthic megafauna of a bathyal basin off southern California: patterns of abundance, biomass and dispersion, Deep Sea Res. Pt A, 30, 907-928, doi:10.1016/0198-0149(83)90048-1, 1983.

Smith, C. R., Grange, L. J., Honig, D. L., Naudts, L., Huber, B., Guidi, L., and Domack, E.: A large population of king crabs in Palmer Deep on the west Antarctic Peninsula shelf and potential invasive impacts, P. R. Soc. B, 279, 1017-1026, doi:10.1098/rspb.2011.1496, 2012.

Snyder, J.: Doppler Velocity Log (DVL) navigation for observationclass ROVs, in: Proceedings of the MTS/IEEEE Oceans 2010 Conference, Seattle, Waschington, USA, 18-23 September 2010, 1-9, doi:10.1109/OCEANS.2010.5664561, 2010.

Söffker, M., Sloman, K. A., and Hall Spencer, J. M.: In situ observation of fish associated with coral reefs off Ireland, Deep-Sea Res. Pt. I, 58, 818-825, doi:10.1016/j.dsr.2011.06.002, 2011.

Solan, M., Germano, J. D., Rhoads, D. C., Smith, C., Michaud, E., Parry, D., Wenzhöfer, F., Kennedy, B., Henriques, C., Battle, E., Carey, D., Iocco, L., Valente, R., Watson, J., and Rosenberg, R.: Towards a greater understanding of pattern, scale and process in marine benthic systems: a picture is worth a thousand worms, J. Exp. Mar. Biol. Ecol., 285-286, 313-338, doi:10.1016/S00220981(02)00535-X, 2003.

Stierhoff, K. L., Neuman, M., and Butler, J. L.: On the road to extinction? Population declines of the endangered white abalone, Haliotis sorenseni, Biol. Conserv., 152, 46-52, doi:10.1016/j.biocon.2012.03.013, 2012.

Tissot, B. N.: Video analysis, experimental design and database management of submersible-based habitat studies, in: Marine habitat mapping technology for Alaska, edited by: Reynolds, J. R. and Greene, H. G., University of Alaska, Fair- 
banks, 157-167, 2008.

Tissot, B. N., Hixon, M., and Stein, D.: Habitat-based submersible assessment of macroinvertebrate and groundfish assemblages at Heceta Bank, Oregon, from 1988 to 1990, J. Exp. Mar. Biol. Ecol., 352, 50-64, doi:10.1016/j.jembe.2007.06.032, 2007.

Wakefield, W. W. and Genin, A.: The use of a Canadian (perspective) grid in deep-sea photography, Deep-Sea Res. Pt. I, 34, 469478, doi:10.1016/0198-0149(87)90148-8, 1987.
Wilson, S. K., Graham, N. A. J., and Polunin, N. V. C.: Appraisal of visual assessment of habitat complexity and benthic composition on coral reefs, Mar. Biol., 151, 1069-1076, doi:10.1007/s00227006-0538-3, 2007.

Wunsch, M. and Richter, C.: The CaveCam-an endoscopic underwater videosystem for the exploration of cryptic habitats, Mar. Ecol.-Prog. Ser., 169, 277-282, doi:10.3354/meps169277, 1998. 